UNITED STATES DEPARTMENT OF THE INTERIOR.

GEOLOGICAL SURVEY

Electrical resistivity well-logging system with solid-state electronic circuitry

by

James H. Scott

U.S. Geological Survey, Denver, Colorado 80225

and

Arnold J. Farstad

Westinghouse Electric Corporation, Boulder, Colorado 80301

Open-File Report 77-144

1977

This report is preliminary and has not been edited or reviewed for conformity with U.S. Geological Survey standards and nomenclature. 


\section{Electrical resistivity well-logging system with solid-state electronic circuitry $1 /$}

\section{Abstract}

An improved 4-channel electrical resistivity well-logging system for use with a passive probe with electrodes arranged in the "normal" configuration has been designed and fabricated by Westinghouse Electric Corporation to meet technical specifications developed by the U.S. Geological Survey. Salient features of the system include solid-state switching and current regulation in the transmitter circuit to produce a constant-current source square wave, and synchronous solid-state switching and sampling of the potential waveform in the receiver circuit to provide an analog dc voltage proportiona? to the measured resistivity. Technical specifications and design details are included in this report.

1) Use of brand names in this report is for descriptive purposes only and in no way constitutes endorsement by the U.S. Geological Survey. 
Introduction

Design specifications for a 4-channel electrical resistivity well-logging system were developed by the U.S. Geclogical Survey (USGS) in October and November 1975. A formal Request for Quotations was issued on December 9, 1975 to solicit bids for development of the system. The Westinghouse Electric Corporation, Geophysical Instrumentation Systems Division of Boulder, Colorado submitted the winning quotation, and subsequently received a purchase order for development of the system. Westinghouse delivered the system for initial testing in June 1976. Extensive laboratory and field tests were made cooperatively by Westinghouse and the USGS, and these tests resulted in several design modifications that were needed to make the system meet specifications. The system was finally accepted by the USGS on November 3, 1976.

This report consists of two parts; Part I is a copy of the technical specifications prepared by the USGS and issued with the Request for Quotations and Part II contains a copy of the Instructions Manual and circuit schematic diagrams (Plates 1-4) provided by Westinghouse. 


\section{Part I}

\section{RESISTIVITY WELL-LOGGING MODULE AND CALIBRATION BOX}

\section{Technical Specifications}

\section{Packaging and Source Power}

The resistivity well-logging module shall be designed to meet Nuclear Instrumentation Module (NIM) specifications and shall fit into a NIM bin (not to be furnished by the contractor) which has the following source voltages available on standard NIM connectors: $110 \mathrm{vac}, \pm 12 \mathrm{vdc}, \pm 24 \mathrm{vdc}$, and $0-300 \mathrm{vdc}$ (floating). See attachment for pin numbers and connector layout diagram. The 0-300 vdc supply is produced by a government-owned H.P. Model 895-A programmable, regulated power supply capable of delivering up to 1.5 amps. All other signal and current input and output connectors on the module shall be standard, commercially available types (BNC or banana chassis-mount connectors preferred), and all shall be mounted on the rear of the module unless otherwise specified. All manual controls, meters, and indicators shall be mounted on the front of the module. The resistivity module shall have a power on-off switch and a pilot light. The calibration box shall be designed to be used outside of the logging truck and shall be packaged in a weatherproof box with a hinged lid covering the switches and input plugs. No power shall be required for use of the calibration box. 


\section{Transmitter Circuit}

The primary function of the transmitter circuit is to produce a constant-current square wave to be delivered to the logging probe through the logging cable. (Neither the probe nor the cable is to be furnished by the contractor.)

2.1 Current waveform generator shall be a solid-state electronic circuit. Mechanical relays or commutators are not acceptable.

2.2 Frequency of the square-wave current shall be $10 \mathrm{~Hz} \pm 1 \mathrm{~Hz}$ with drift iess than 0.1 percent per degree $C$ with the module operated in environmental temperatures ranging from $10^{\circ}$ to $3 n^{\circ} \mathrm{C}$.

2.3 Resistivity ranges shall be $10,20,50,100,200,500,1,000$, $2,000,5,000$, and 10,000 ohim-meters (fur1 scale) selectable by a current-control switch. Current for the $10 \mathrm{ohm}-\mathrm{m}$ range shall be approximately $100 \mathrm{~mA}$. Current output shall be floating (not connected to chassis ground). For any given resistivity range the square-wave current shall be held constant to within \pm 1 percent of its intended value regardless of load resistance for loads ranging from 0 to maximum values shown in Table 2.4. A warning-indicator light shall be provided which will turn on if current deviates more than \pm 2 percent from its intended value. 
2.4 Table of resistivity ranges and maximum resistive load values for current regulation of \pm 1 percent or better:

Resistivity Range

10 ohm-meters
20
50
100
200
500
1,000
2,000
5,000
10,000

Maximum Load $\underline{\text { Resistance }}$

500 ohms
1,000
2,500
5,000
10,000
10,000
20,000
20,000
50,000
50,000

3. Receiver Circuit

The primary function of the receiver circuit is to accept four separate potential signals simultaneously from each of the four potential electrodes on the borehole probe at normal configuration spacings of $8,16,32$, or 64 inches $(20,40,80,160 \mathrm{~cm})$, to reference each input signal to a common surface ground electrode, synchronously rectify and sample each signal, and produce four output dc voltages, each one proportional to measured resistivity at one of the four probe electrodes. The four dc voltages will be. recorded on a TI (Texas Instruments) Servo/riter II recorder (4-channels) with a full-scale 10-inch $(25.4-\mathrm{cm})$ span sensitivity of $100 \mathrm{mV}$ and a minimum input impedence of 100,000 ohms. (Recorder is not to be furnished by the contractor.)

3.1 The receiver circuit for each one of the four input channels shall have an input impedence of at least 1 megohm and an output impedence suitable for driving the TI recorder described above. Input shall be floating (not connected to chassis ground). 
3.2 A probe electrode spacing control switch with positions for the $8,16,32$, and $64-$ inch $(20,40,80,160-\mathrm{cm})$ spacings sha 11 be provided for each channel so that the input signal from any one of the four probe electrodes can be connected to any one of the four receiver channels.

3.3 A resistivity-multiplier control switch having $X 10, X 1$, and X0.1 positions shall be provided for each receiver channel to extend the range of resistivity (selected on the transmitter module) one decade above or below the normal (X1) setting.

3.4 The potential signals in each of the four receiver channels shall be synchronously rectified, sampled, averaged, and smoothed in the following manner. An average voltage representing the rectified potential signal shall be obtained and updated every full cycle. The average shall be formed by blanking out the first $40 \mathrm{~ms}$ of each half cycle, integrating the signal over the last $10 \mathrm{~ms}$, and then averaging the integrated signals over both half cycles after synchronous rectification. Blanking and sampling periods shall be gated by a timing signal from the transmitter circuit. Smoothing of the average sample shall be accomplished by a calibrated time constant control (step switch) to provide a range of time constants from 0 to 5 seconds. The following time constant switch setting shall be provided: $0,0.1,0.2,0.5,1.0$, 2.0, and 5.0 seconds. 
3.5 The output voltage signals (after scaling, rectification, sampling, averaging, and smoothing) shall be routed through 10-turn linear attenuator controls (one for each receiver channel) with miniature calibrated $(0-1,000)$ dials and locking levers. Full-scale output voltage of $100 \mathrm{mV}$ shall be available at a setting of 500 on the attenuator controls, and $200 \mathrm{mV}$ at a setting of 1,000 . The attenuated signal from each channel shall be connected to four separate "recorder" connectors at the rear of the module.

3.6 A 3-position recorder calibration switch shall be provided for each channel to set or verify recorder zero and full-scale points. The "zero" and "full-scale" positions of the switch shall be momentary with spring return to the "log" center position of the switch. The "zero" check point shall be obtained by shorting the signal input to the receiver channel. The "full-scale" check point shall be obtained by connecting a voltage sample of the transmitter current waveform obtained across a series resistor with a value such that the sampled voltage is equal to the full-scale voltage from the 8 -inch $(20-\mathrm{cm})$ potential electrode on the probe.

3.7 Four pairs of BNC chassis mount connectors (one pair for each receiver channel) shall be mounted on the front of the module to facilitate connecting an oscilloscope for test purposes. One connector of each pair shall be connected so that the input signal to the receiver channel can be observed, and the 
other shall be connected so that the signal can be observed after the leading $40 \mathrm{~ms}$ is blanked out, but prior to integration of the last $10 \mathrm{~ms}$ of each half cycle.

\section{SP Blocking Circuit}

The primary function of the spontaneous potential (SP) blocking circuit is to minimize the SP roltage superimposed on the resistivity square-wave signal from the potential electrodes on the probe reference to the surface ground electrode. Two different techniques for biocking the SP shall be provided by the circuit: (1) a non-polarized capacitor, and (2) a voltage bucking circuit, both connectable in series with the input from the common surface ground potential electrode. The following three alternative methods of SP biocking shall be seiectabie by control switch(es): (1) the capacitor only, or (2) the bucking circuit only, or (3) both the capacitor and the bucking circuit. The bucking circuit shall have a range of $-500 \mathrm{mV}$ to $+500 \mathrm{mV}$, continuously adjustable by a 10-turn linear potentiometer control with a calibrated dial. Two input connectors for the surface ground electrode shall be available and shall be connected in common; one shall be located on the front and the other on the rear of the module.

\section{Calibration Box}

The primary function of the calibration box is to provide selectable resistance networks for checking the calibration of the entire resistivity system from the borehole probe to the recorder. The box shall contain one selector switch for simulating contact 
resistances of $50,500,5,000$, or 50,000 ohms in both the potential and current circuits. It shall have a second switch for selecting simulated resistivities of 10,100,1,000, and 10,000 ohm-meters, and a third switch for selecting electrode spacings of $8,16,32$, and 64 inches $(20,40,80,160 \mathrm{~cm})$. The box shall have labeled input/output plugs (chassis mount female banana connectors) for external connections to the $A, B, M$, and $N$ current and potential electrodes. The box shall be ruggediy designed so that it can be operated reliably and easily out-of-doors in fair or foul weather. A hinged lid shall be provided to cover all three switch knobs and the input/output plugs to protect them from rain, mud, dirt, and mechanical damage. 


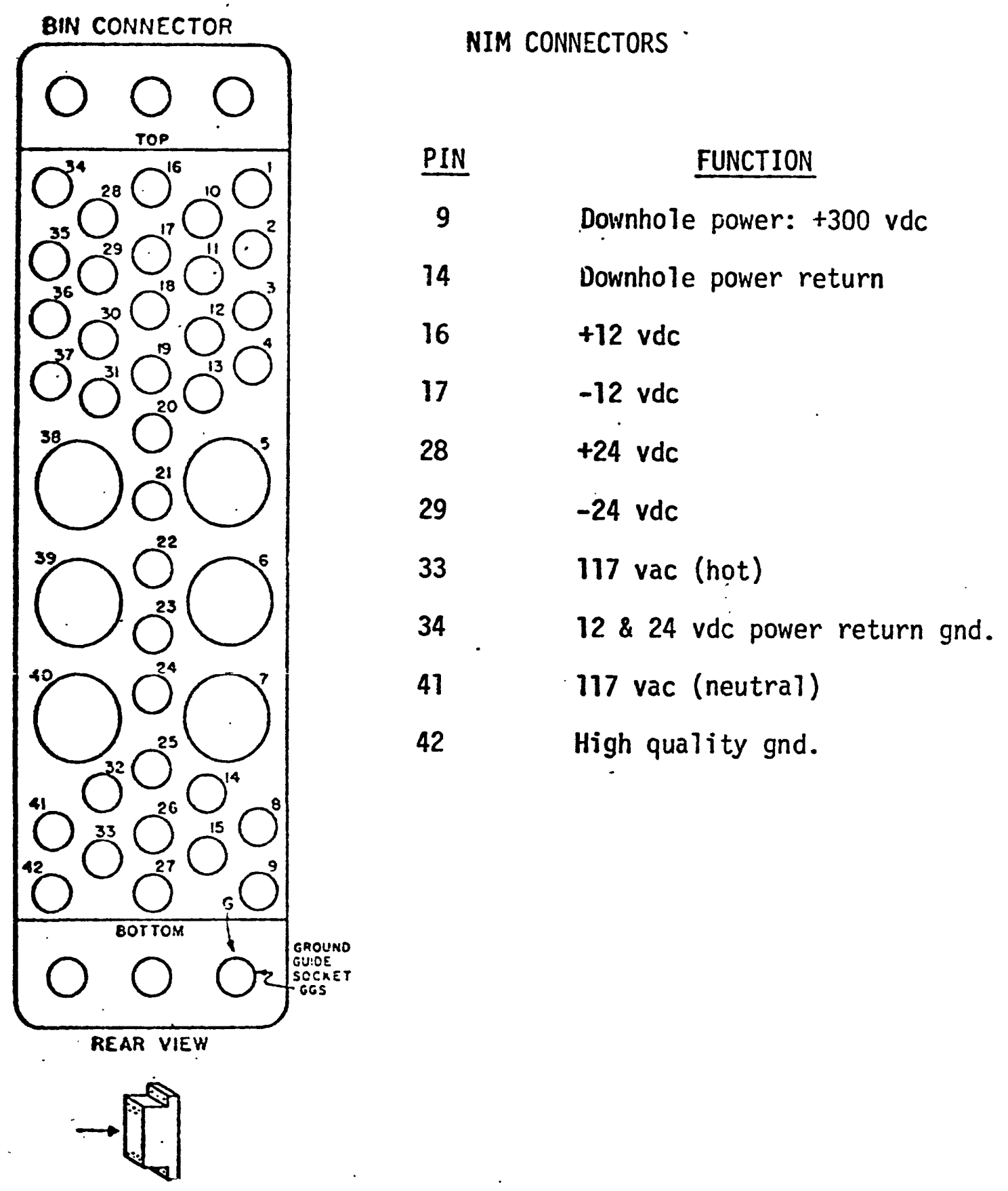




\section{Part II}

INSTRUCTION MANUAL

RESISTIVITY WELL-LOGGING MODULE

AND CALIBRATION BOX

MODEL B1O1

June 1976

WESTINGHOUSE ELECTRIC CORPORATION

Geophysical Ins trumentation Sys tems

5441 Western Avenue

Boulder, Colorado 80301

(3n3) 443-7961 
Part II

RESISTIVITY WELL-LOGGING MODULE AND CALIBRATION BOX

Instruction Manua 1

Model B101

\section{Introduction}

The Westinghouse Model B101 Resistivity Well-Logging Module is a completelv solid state high voltage, current-regulated subsystem designed to monitor electrical resistivity of the earth as a function of depth down a borehole. The transmitting system and receiving system are synchronized in time and utilize the concent of coherent detection for maximum noise rejection performance. Both the transmitter and receiver are packaged in a NIM (Nuclear Instrumentation Module) configuration and are designed to interface directly with existing NIM Bins used in conventional logging trucks. The receiver module is capable of recording four channels of information simultaneously with each channel selectable to either a $8 ", 16 ", 32^{\prime \prime}, 64 "(20,40,80,160 \mathrm{~cm})$ NRRMAL log probe spacing. The transmitter operates from a floating 30 volt dc supply with selectable square wave regulated output curre - of from $100 \mu \mathrm{A}$ to $100 \mathrm{~mA}$ depending on the full scale $r$ istivity range chosen on the instrument front panel.

A calibration box is also included with this system to provide selectable resistance networks for checking the calibration of the entire resistivity system from the borehole probe to the recorder. 


\section{Theory of Operation}

The theory of operation of the Model B101 Resistivity System consists of applying a precisely-regulated square-wave current to a borehole probe at normal configuration spacings of $8,16,32$, and 64 inches $(20,40,80,160 \mathrm{~cm})$ and synchronously integrating and sampling the received signal as the probe is lowered down the hole. A square-wave frequency of $10 \mathrm{~Hz}$ is generated by the transmitter, with selectable regulated output currents of from $100 \mu \mathrm{A}$ to $100 \mathrm{~mA}$ depending on the full scale range of resistivity selected. Full scale resistivities of from 10 ohm-meters to $10,000 \mathrm{ohm}$-meters are selectable via a front panel switch tied to the current regulating circuits in the transmitter. Additional control of resistivity range is obtained by a gain switch in the receiver providing a resistivity muitipijer of $\ddot{x} 0 . \dot{i}, \ddot{x} i$, and X10. The transmitted currents corresponding to the resistivity full-scale ranges are as follows:

\begin{tabular}{|c|c|}
\hline$\frac{\text { Transmitted }}{\text { Amperes }} \frac{\text { Current }}{}$ & Full $\frac{\text { Scale }}{\Omega} \frac{\text { Resistivity }}{\Omega-m}$ \\
\hline $\begin{array}{l}.1 \\
.05 \\
.02 \\
.01 \\
.005 \\
.002 \\
.001 \\
.0005 \\
.0002 \\
.0001\end{array}$ & $\begin{array}{r}10 \\
20 \\
50 \\
100 \\
200 \\
500 \\
1,000 \\
2,000 \\
5,000 \\
10,000\end{array}$ \\
\hline
\end{tabular}

The resistivity subsystem is designed around an existing multi-spacing resistivity probe system with an infinite source electrode represented by a length of armored cable insulated from the probe by 50 feet $(15 \mathrm{~m})$ 
of insulation. The probe is diagramed as follows:

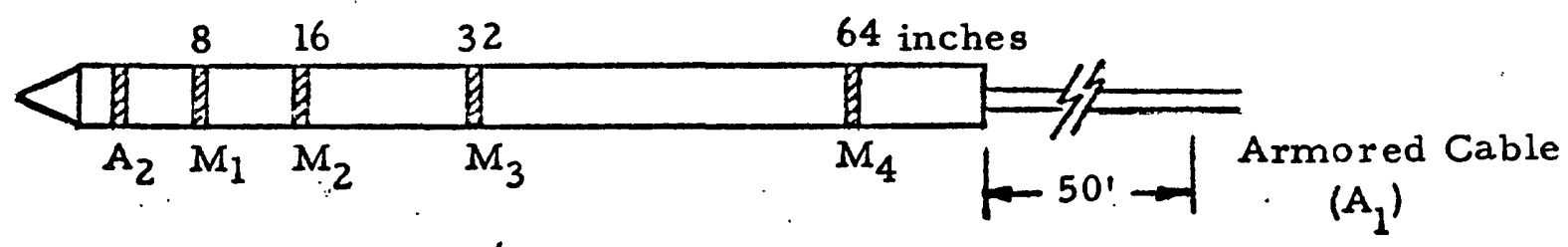

The resistivity for the different probe spacings is computed as follows:

where

$$
\rho=4 \pi \overline{A M} \frac{E}{I} \text { ohm-meters }
$$

$\overline{\mathrm{AM}}$ is the electrode spacing in meters,

$E$ is the received voltage in volts, and

I is the applied current in amps.

The geometric scale factor $4 \pi$ AM is:

\begin{tabular}{|c|c|c|c|c|}
\hline$\underline{A M}$ & & $(4 \pi \quad A M)$ & $\frac{1}{4 \pi A M}$ & $\underline{G}$ \\
\hline ches & meter & & & \\
\hline $\begin{array}{r}8 \\
16 \\
32 \\
64\end{array}$ & $\begin{array}{r}.203 \\
.406 \\
.812 \\
1.624\end{array}$ & $\begin{array}{r}2.5515 \\
5.1031 \\
10.2062 \\
20.4123\end{array}$ & $\begin{array}{l}.39193 \\
.19595 \\
.097979 \\
.04899\end{array}$ & $\begin{array}{l}.25515 \\
.51031 \\
1.0206 \\
2.0412\end{array}$ \\
\hline
\end{tabular}

Assuming that the recorder sensitivity is kept constant at 100 millivolts, we get

$$
\mathrm{GE}=100 \mathrm{mV}
$$

where

$G$ is the receiver gain.

The current range switching technique described previously implies that

$$
\rho X I=1 \text { and } E=\frac{\rho I}{4 \pi A M}=\frac{1}{4 \pi A M} \mathrm{mV} \text {. }
$$


Thus, $G=\frac{100 \mathrm{mV}}{\frac{1}{4 \pi \mathrm{AM}}}$ and the receiver consists of 4 individual channels with the appropriate gain as shown above.

\section{Transmitter Circuit Concepts}

The transmitter in the Westinghouse Model B101 Resistivity Logging Module utilizes a full wave bridge of four high voltage MJ425 power transistors optically coupled to a precise $10 \mathrm{~Hz}$ square wave via HP 5082-4371 optical isolators. Current regulation is achieved by a series-regulating transistor whose impedance change is inversely proportional to the amount the actual current exceeds the current called for by the front panel resistivity setting. A current deviation LED (light emitting diode) light senses when the actual current differs from the current cailied for by the current demanded by the resistivity setting, (i.e., when the impedance across the borehole probe is too great for current regulation to occur). A built-in $5 \mu \mathrm{s}$ dead time is included in the switching configuration to insure that each pair of transistors in the output bridge are fully turned off before the alternate pair is turned on.

The transmitter logic operates on a regulated 8 volt supply which derives its source power from the +24 volt power supply in the NIM Bin. Receiver Circuit Concepts

The primary function of the receiver circuit is to accept separate potential signals from each of the four potential electrodes on the borehole probe at normal configuration spacings of $8,16,32$, or 64 inches $(20,40,80,160 \mathrm{~cm})$, to reference each input signal to a common 
surface ground electrode, synchronously rectify and sample each signal, and produce four output dc voltages, each one proportional to measured resistivity at one of the four probe electrodes. The four dc voltages are recorded on a TI Servo/riter II recorder (4-channels) with a full-scale 10 -inch $(25-\mathrm{cm})$ span sensitivity of $100 \mathrm{mV}$ and a minimum input impedance of 100,000 ohms.

The receiver circuit for each input channel has an input impedance greater than 10 megohms. The input preamplifiers are Burr Brown 3660 Differential Amplifiers. The probe electrode spacing control switch selects any input signal from any one of the 4 probe electrodes and connects that signal to any one of the 4 amplifier channels, while automatically setting the appropriate gain factor for each channel.

The potential signals in each of the four receiver channels are synchronously integrated, sumed, and sampled before being filtered in a selectable low pass filter prior to recording. The integration and summing is performed in such a way as to present an average of the signals occurring over the previous two half cycles to the sample and hold circuit at the time the sample and hold pulse is generated. The integration period occurs during the last $10 \mathrm{~ms}$ of each $50 \mathrm{~ms}$ half cycle period, thus eliminating the possibility of any switching transients having an effect on the integrated output. Sampling occurs at the end of each $50 \mathrm{~ms}$ half cycle period and the sampled output is the average value of the previous two half cycles of signal.

The low pass filter has selectable time constants from approximately 0 to 5 seconds in steps of $0, .1, .2, .5,1,2$, and 5 seconds. A 
calibrated attenuator is included at the output of the low pass filters. This attenuator has a built in attenuation of $20 \mathrm{~dB}$ (factor of 10 ) to reduce a full scale output voltage of 2 volts to $200 \mathrm{mV}$ for compatibility with the TI Recorder full scale range of $100 \mathrm{mV}$. The attenuator dials are normally set to about .5, giving another $6 \mathrm{~dB}$ attenuation and a full scale output of $100^{\circ} \mathrm{mV}$ to the recorder. The attenuator dials can be varied above or below the .5 setting by whatever amount is necessary to make the unit perfectly compatible with the recorder being used with the system.

A 3-position recorder-calibration switch is provided for each channel to set or verify recorder zero and full-scale points. The "zero" and "full-scale" positions of the switch are momentary with spring return tn the "log" center position of the switch. The "zero" check point is obtained by shorting the signal input to the receiver channel. The "full-scale" check point is obtained by connecting a voltage sample of the transmitter signal such that the sampled voltage is equal to the full-scale voltage from the 8 -inch potential electrode on the probe.

Four pairs of BNC chassis mount connectors (one pair for each receiver channel) are included on the front of the module to facilitate connecting an oscilloscope for test purposes. One connector of each pair is connected so that the input signal to the receiver channel can be observed, and the other is connected so that the signal can be observed after the leading $40 \mathrm{~ms}$ is blanked out, but prior to integration of the last $10 \mathrm{~ms}$ of each half cycle. 


\section{SP Bucking Circuit}

The primary function of the SP bucking circuit is to minimize the SP voltage superimposed on the resistivity square-wave signal from the potential electrodes on the probe reference to the surface ground electrode. Two different techniques for blocking the SP are provided by the circuit: (1) an ac coupling capacitor, and (2) a voltage bucking circuit, both connectable in series with the input from the common surface ground potential electrode. The following three alternative methods of SP bucking are selectable by control switch(es): (1) the capacitor only, or (2) the bucking circuit only, or (3) both the capacitor and the bucking circuit. The bucking circuit has a range of $-500 \mathrm{mV}$ to $+500 \mathrm{mV}$, continuous $7 y$ adjustable by a 10 -turn linear potentiometer control with a calibrated dial. Two inplit cornectors for the surface ground electrode are available and are connected in common; one is located on the front and the other on the rear of the module. Calibration Box

The primary function of the calibration box is to provide selectable resistance networks for checking the calibration of the entire resistivity system from the borehole probe to the recorder. The box contains a selector switch for simulating contact resistances of 50 , $500,5,000$, or 50,000 ohms in both the potential and current circuits. It has a second switch for selecting simulated resistivities of 10 , $100,1,000$, and 10,000 ohm-meters, and a third switch for selecting electrode spacings of $8,16,32$, and 64 inches $(20,40,80,160 \mathrm{~cm})$. The box has labeled input/output plugs (chassis mount female banana connectors) for external connections to the $A, B, M$, and $N$ current. 


\section{Physical Description}

The Westinghouse Resistivity Well-Logging Module Model B101 is packaged in two Nuclear Instrumentation Modules (NIM). The transmitter is packaged in a double-width module and the receiver is packaged in a six-width module. The dimensions of the double-width module are $9^{\prime \prime} .(23 \mathrm{~cm}) \times 4^{\prime \prime}(10 \mathrm{~cm}) \times 10^{\prime \prime}(25 \mathrm{~cm})$ and the six-width modules are 9" $(23 \mathrm{~cm}) \times 12^{\prime \prime}(30 \mathrm{~cm}) \times 10^{\prime \prime}(25 \mathrm{~cm})$. A photograph of the front pane1 of each of these modules is given in Figure 1 and 2. 


\section{OFFSET BALANCE PROCEDURE \\ WESTINGHOUSE RESISTIVITY LOGGING SYSTEM B101}

\section{Receiver Module}

1. Set Recorder Calibrate switch to zero on all channels.

2. Set SP Buck switch to AC couple on all channels.

3. Set SP dial to midscale (500) on all channels. Set Resistivity Multiplier switch to $x 1$ on all channels.

4. Balance $A_{1}, A_{6}, A_{11}$, and $A_{16}(B B 36601)$ to zero. Volts dc at pin 9 of each amplifier.

5. Balance amplifiers $A_{3}, A_{4}, A_{8}, A_{9}, A_{13}, A_{14}, A_{18}$, and $A_{19}$ as close to zero as possible. This will be more difficult to balance since switching operations are taking place in the integrate and integrator quench commands while offset balance adjustments are made.

6. Finally, balance Sample and Hold Amplifiers HA2425-5 for zero volts output at pin 6 of the output amplifiers $A_{5}, A_{10}, A_{15}$, and $A_{20}$ (BB3542).

\section{Transmitter Module}

1. A2 (MONO OP 5): Connect shorting jumper between pin 5 (+ input) and J1-14 (neg. side of $200 \mu$ f electrolytic capacitor). Connect DVM (digital volt meter) between pin 10 (output) and pin 5 and adjust $R-30$ to zero reading on DVM.

2. $A 1$ (BB3580J): Rough balance: Leave shorting jumper on $A 1$ (pin 5 to J1-14), connect DVM between pin 1 of A1 (output) and pin 5 of 
A2 and adjust R-35 to zero reading on DVM. Fine balance: Disconnect shorting jumper, connect module for normal operation (with 100-300 v current source and load on current output, J5-13 to J5-14). Monitor dc current into $\mathrm{J} 1-9$ or $\mathrm{J}-14$ and adjust to proper value on $10 \mathrm{~K} \Omega \mathrm{m}$ range $(97.7 \mu \mathrm{A})$. 


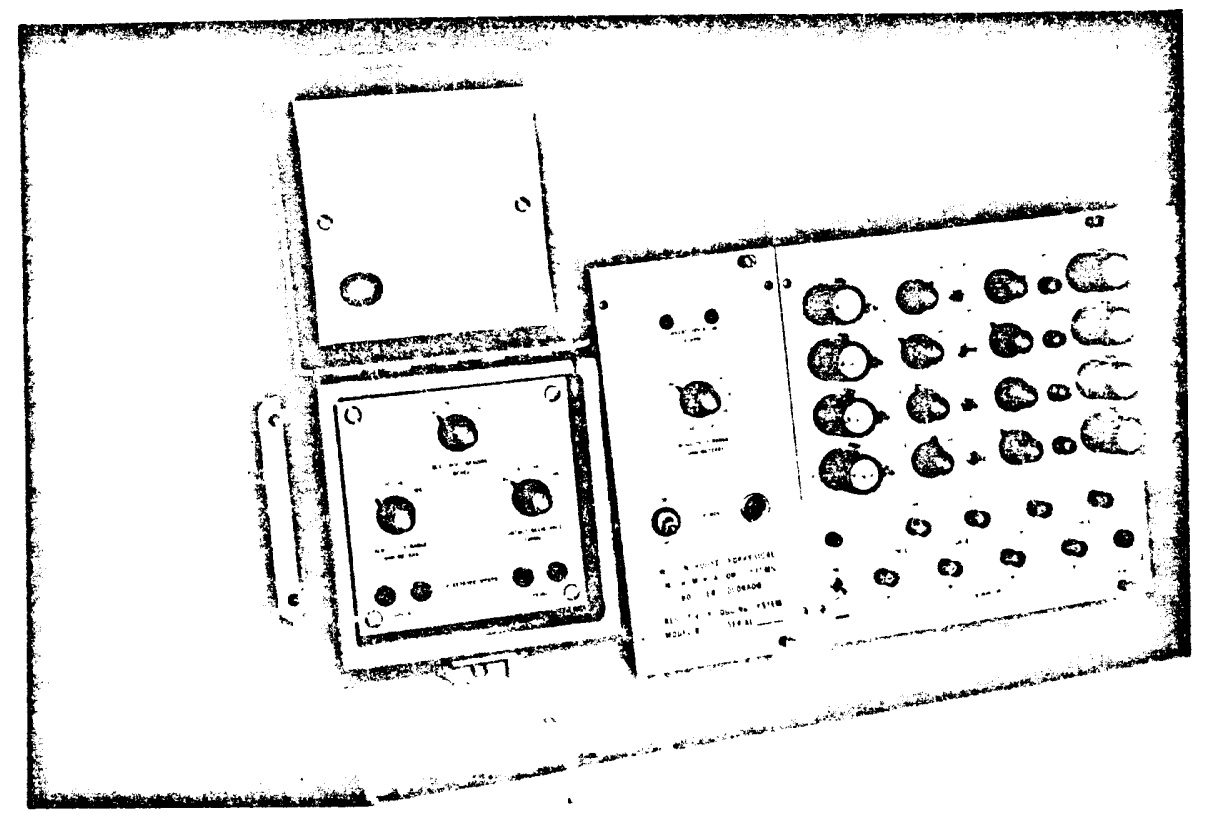

Figure 1 Westinghouse Resistivity Logging System Model B101 
옴

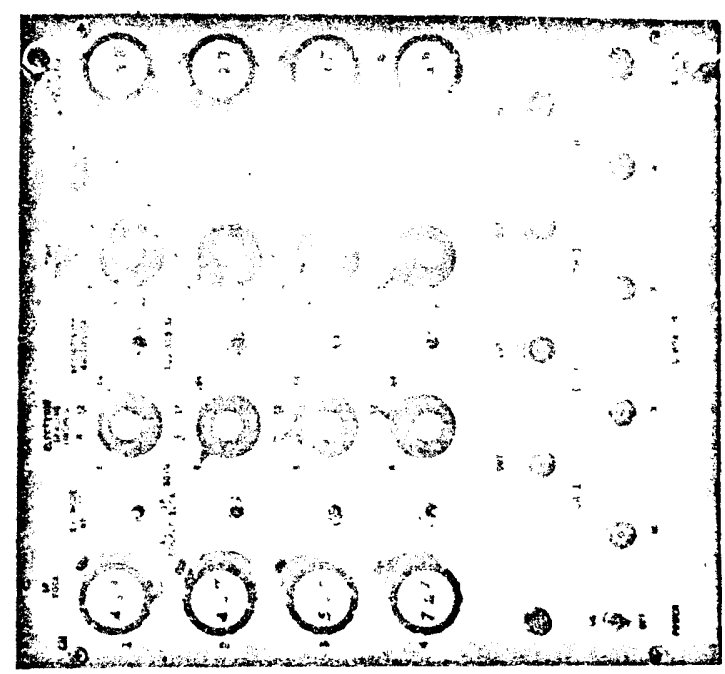

峁

E

$\stackrel{9}{9}$

㤐

0
0
0
0
0
0
0
0
0
0
0
0

8

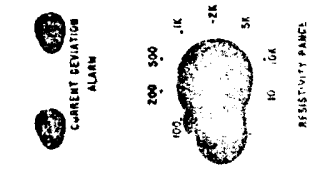

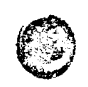

落

$N$
0
3
0
0
0.4 


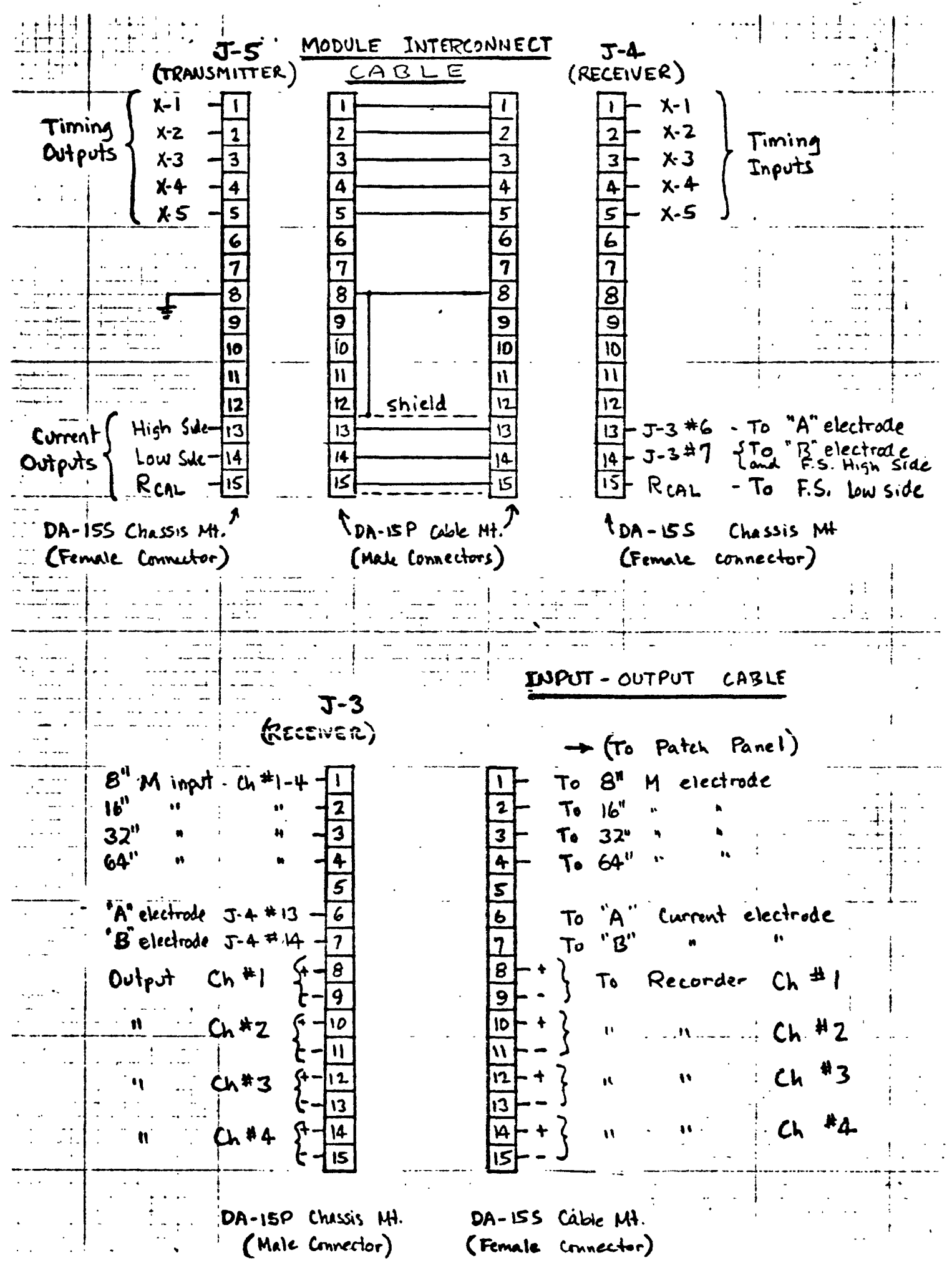

Figure 3.- External cables for I/O and module interconnection. 


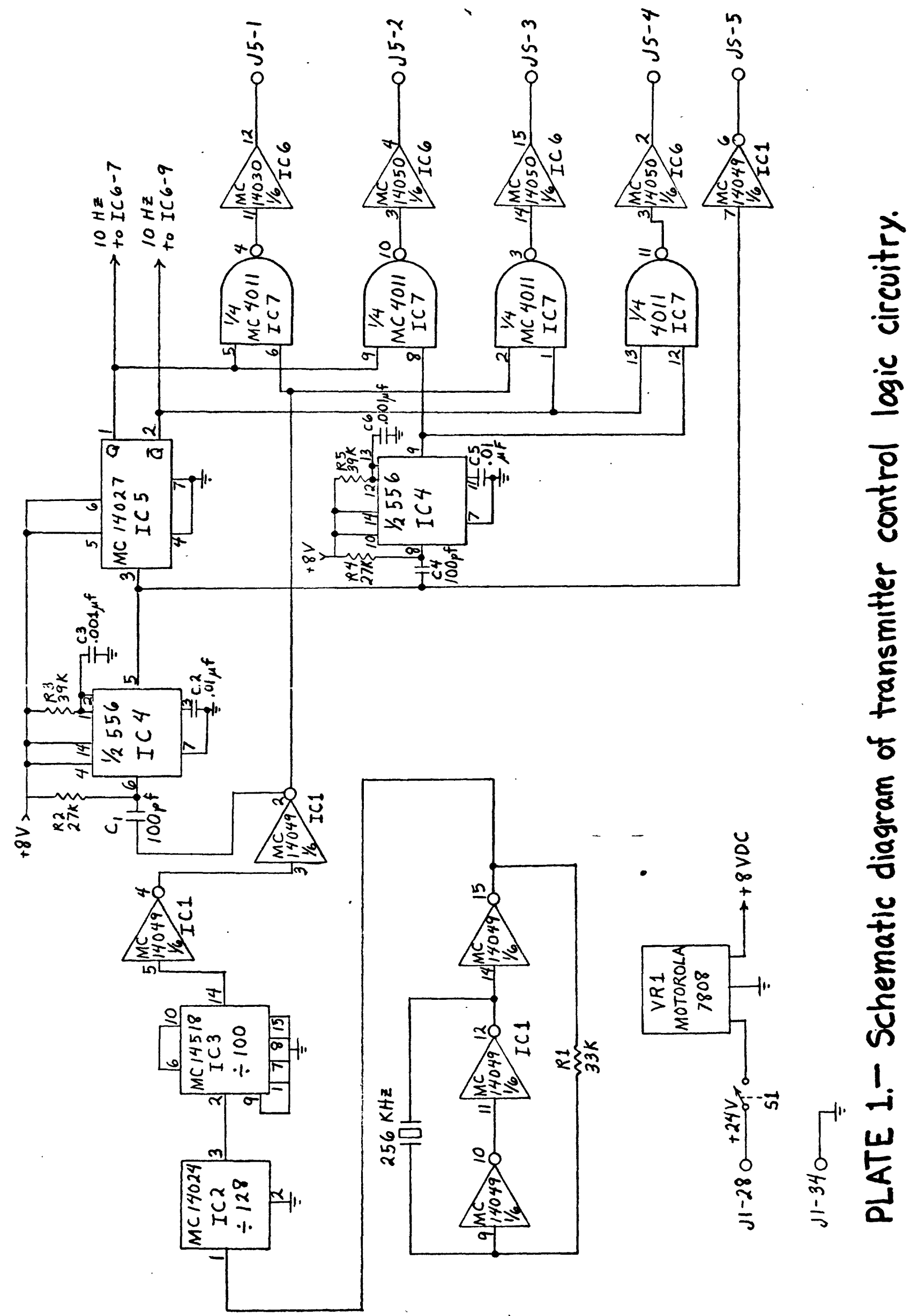




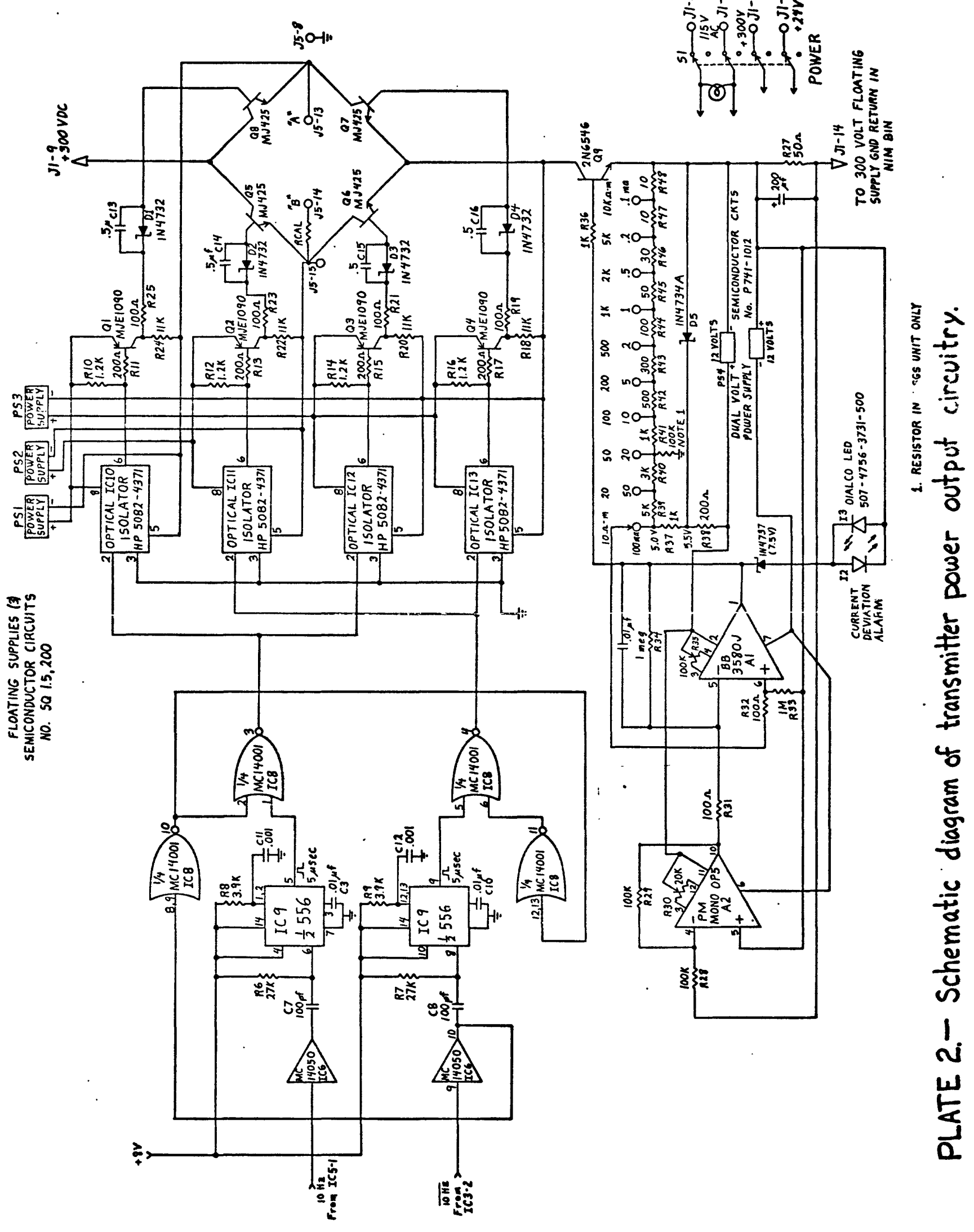




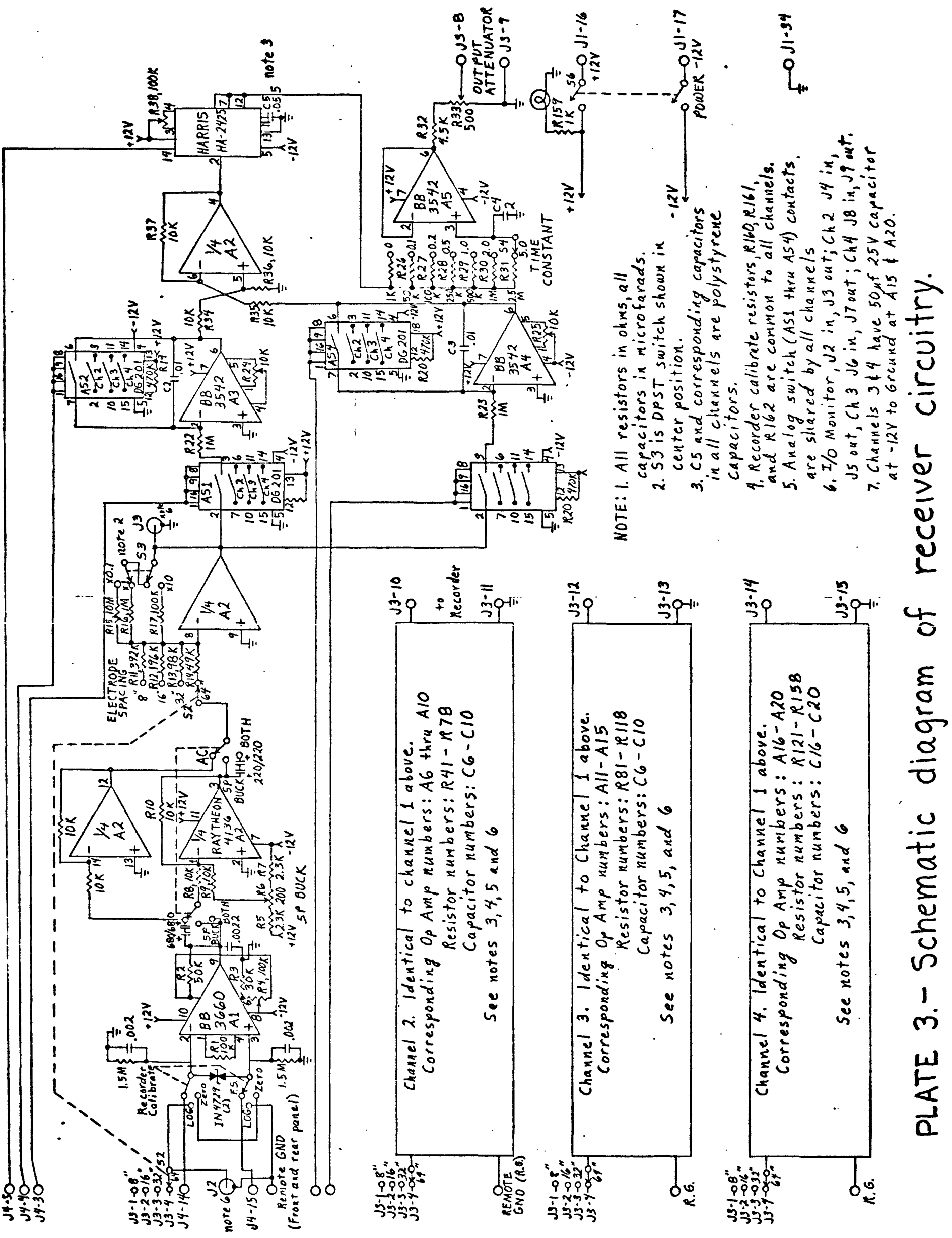




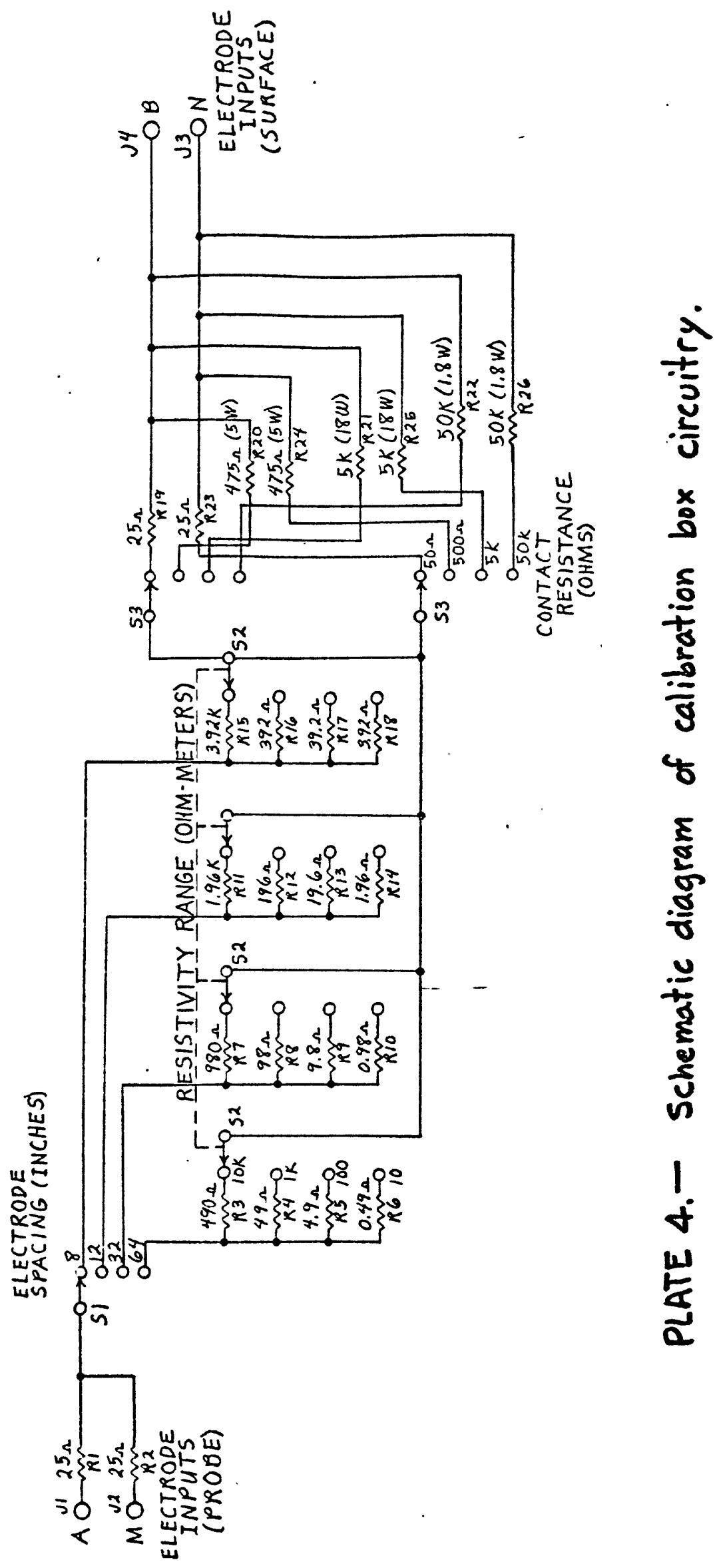

$-28-$ 